\section{Abstract}

In post-disaster recovery, optimising psychosocial support is important for all groups of the population, yet young adults have tended to be overlooked as a demographic in their own right. Research was conducted to seek the perspectives of young adults through the narrative of their experiences in the years following the 2009 Gippsland bushfires. One emergent theme in the findings highlighted the importance of information and communication during and after events.

Participants in this research sought information and support via social media and virtual communities. These sites traverse localised, place-based solutions, enabling young people to communicate over large geographical areas. The platforms aid dynamic and rapidly evolving support by sharing information, feelings and ideas. This research also highlighted the need to identify the gaps in information processes and support systems for young adults and to ensure youthspecific information is included in formal communications. Possible solutions are outlined taking into consideration the perspectives offered by the study participants.

BASED ON A PAPER PRESENTED AT THE AUSTRALIA \& NEW ZEALAND DISASTER \& EMERGENCY MANAGEMENT CONFERENCE 2020.

\title{
Beyond place-based: the role of virtual communities via social media in young adult recovery
}

Peer Reviewed

\section{Dr Julie Willems ${ }^{1}$}

Dr Rouve Jan Forbes ${ }^{1}$

Dr Margaret Simmons ${ }^{1}$

1 Monash Rural Health, Monash University, Churchill, Victoria.

\section{SUBMITTED}

2 December 2020

\section{ACCEPTED}

18 December 2020

DOI

www.doi.org/10.47389/36.2.48

\section{(c) (1) (2)}

(C) 2021 by the authors. License Australian Institute for Disaster Resilience, Melbourne, Australia. This is an open access article distributed under the terms and conditions of the Creative Commons Attribution (CC BY) license (https:// creativecommons.org/ licenses/by/4.0/).

\section{Introduction}

'Black Saturday' refers to the catastrophic bushfire events across Victoria in February 2009 (Department of Human Services DHS 2009, Teague et al. 2010). As part of Black Saturday, 4 major fire complexes (the Delburn, Bunyip, Churchill and Wilsons Promontory complexes) raged across the Gippsland region in eastern Victoria and were collectively referred to as the 2009 Gippsland bushfires.

The Australian Bureau of Statistics (ABS 2013) defines young adults as those aged between $18-34$ years. This age range is marked as a time of transition, where people develop independence that might include moving away from the family home, finding a partner, studying or starting a career. However, as a specific age cohort, young adults have tended to be overlooked as research participants in post-disaster research (Peek et al. 2016). If included in research, their specific psychosocial recovery has not been examined (Cox et al. 2017).

Research was conducted on the longer-term psychosocial recovery of young adults in the years beyond the 2009 Gippsland bushfires. Several themes emerged from the research. One was the role of acknowledgment (Forbes, Willems \& Simmons 2021). This article explores the theme of deficiencies in youth-specific information and communication during and following disasters. From the perspective of the young adults in the research, it highlights the role of social connectedness in the recovery of young adults through social media and virtual communities.

\section{Information and communications in psychosocial recovery}

For those who experience emergencies and disasters - and their aftermath - the need for accurate and timely local information is vital. It provides opportunities for connection 
to community and recovery supports (Au 2011, Pato 2016). Recovery frameworks indicate that information is central to success. During the 2009 Gippsland bushfires, information was primarily delivered by the Australian Government and emergency services organisations (Blanchard et al. 2010, Vieweg et al. 2010). Such 'formal' communication channels present challenges in that information can be one-directional and can lag behind events as they unfold (Willems 2015).

The question of how to optimise communication to support specific groups such as young adults during emergencies and in their post-disaster psychosocial recovery is crucial to answer. According to Au (2011), at the time of the Black Saturday bushfires and in the immediate aftermath, there appeared to be no coordinated and overarching approaches for optimising communication. Young adults, and indeed everyone, require information that is understandable, trustworthy, ageappropriate, readily available and that enables access support to deal with the emerging and ongoing consequences of the event (Bird et al. 2012, Blanchard et al. 2010, Lovari \& Bowen 2019, Paton \& Irons 2016, Taylor et al. 2012).

Social media sites are an increasingly popular and multidirectional means of disseminating information during and after disasters. They are also known as 'back channel communication', which refers to informal communication that may travel in tandem with (and sometimes in advance of) official or formal channels (Willems 2015). They can also serve as a primary source for individuals and communities following a disaster, providing a conduit for accessing support and linkages (Page-Tan 2020). This involves 'a grassroots effort where social media is used in a number of ways to support the safety of the community' (White 2012 p.187) and for psychosocial supports in the aftermath.

\section{Beyond place: virtual communities and social media}

Deficiencies in youth-specific information and gaps in the delivery of information during and after disasters have been identified (Forbes, Jones \& Reupert 2012; Fletcher et al. 2016). Research suggests that formal communication channels are not the best for the age-specific cohort of young adults. Young adults communicate and seek information during and in the aftermath of emergencies and disasters through social media. Kaplan and Haenlein (2011) define social media as 'a group of Internet-based applications that build on the ideological and technological foundations of Web 2.0 [allowing] the creation and exchange of User Generated Content' (p.59). The interactivity of social media promotes user-generated content through collective knowledge creation and 2-way communication (Beetham, McGill \& Littlejohn 2009, Lovari \& Valentini 2020, Willems 2013). In addition, Lovari and Valentini (2020) argue that social media can be empowering and particularly useful during crises. Dufty $(2012$, p.43) progresses this notion of empowerment by relating it to providing 'power to the people' in its enabling of peer-to-peer interactions.

Social media has 3 main types of users: 'prosumers', 'tacit consumers' and 'non-engagers' (Fergie, Hunt \& Hilton 2016). Prosumers actively produce and consume social media content
(Toffler 1980) as distinguished by those who only consume the content. Young adults stand out as a demographic that embraces social media platforms and uses them frequently (Smith \& Anderson 2018) as prosumers and consumers in comparison with other age groups (Anderson \& Jiang 2018, We are Social 2020). This is especially so in contrast to older age groups with the tendency to be 'non-engagers' of social media, however the global COVID-19 pandemic has been a catalyst to bring older demographics online (We are Social 2020). Social media use by young adults varies across platforms. In recent years, social media preference by young adults has shifted from Facebook, now viewed as a social media platform for 'mum' (Pangrazio \& Selwyn 2018, p.4) to other forms of social media such as Snapchat and Instagram (Anderson \& Jiang 2018).

During emergencies and disasters, young adults also use social media to connect with others to contact and locate family and friends (Beetham, McGill \& Littlejohn 2009, Lovari \& Valentini 2020). Social media is also used to access virtual communities for support. Virtual communities have existed on the Internet for almost a quarter of a century (Ridings \& Gefen 2004) and they offer spaces to share information, feelings, ideas and support (Kaplan \& Haenlein 2011). According to Palen and coauthors (2009), social networking can be described as 'virtual destinations'; places that enable people to communicate over wide geographical areas. Ridings and Gefen (2004) contend that the main reason people join virtual communities is for information exchange but also to seek friendship and social support that extend their social network of family and friends. Virtual communities can therefore lead to greater engagement with others through knowledge sharing (Dufty 2012, Shanahan \& Elliot 2009, Taylor et al. 2012). Palen and colleagues (2009) argue that virtual communities may fill a social void that has arisen in conventional communities. It is important to remember that these 'virtual destinations' are dynamic and rapidly evolving spaces that allow people to access support beyond their placebased support networks (Fugate 2011; Keim, Noji \& Keim 2011; Lovari \& Valentini 2020)

Dufty (2012) suggests that social media has the potential to build community disaster resilience in a variety of ways, including through the development of social capital. According to the Organisation for Economic Co-operation and Development (OECD 2001), social capital has such structural and psychological elements as the networks of personal relationships. This fosters a sense of mutual understanding that helps people to live and work together effectively. Social capital is generated through networking, leadership and support systems as well as disaster risk management (Keim, Noji \& Keim 2011). In the context of disaster, social media can increase social capital, leading to better outcomes (Page-Tan 2020). Howell and Taylor (2012) found that Facebook was useful in empowering young people to be active participants in community response networks, arguing that ' $[i]$ $\mathrm{n}$ the immediate aftermath, the reach of these social networks assisted those who were recovering from disaster by rapidly connecting them with resources to obtain help' (p.6). Howell and Taylor (2012) suggest that social media's main 'strengths of timely information exchange and promotion of connectedness, 
were able to act as sources of psychological first aid in the early stages of disaster and assist in supporting aspects of community resilience' (p.7). Therefore, delivery of information in an ageappropriate way is vital for young adults to be involved and to set up alternate supports. This is reinforced if recovery plans contain specific actions and activities that are targeted to the needs of young people and that 'recovery is best achieved when the affected community is able to exercise a high degree of selfdetermination' (DHSEMB 2013, p.15).

Much psychosocial support and approaches to recovery are primarily place-based. Yet many young adults are a transient part of the population. They also seek information and support from virtual communities. Beyond place-based solutions, back channels allow people to communicate over large geographical areas and enables dynamic and rapidly evolving support by sharing information and enabling personal and social engagement and suggestions. Through these channels, information is dynamic, interactive and current, as compared to formal channels that may lag behind changeable and hazardous local conditions (Willems 2013).

\section{Methodology}

Research was conducted on the psychosocial recovery of young adults 6 to 7 years after the 2009 Gippsland bushfires by gathering qualitative and quantitative data from 20 young adults who had been affected. Ethics approval was granted from the Monash University Human Research Ethics Committee (CF14/3555 - 2014001877), with data collection taking place between April 2015 and December 2016.

Two data collection instruments were used for the research. The first was a survey containing open-ended questions and the second was a semi-structured interview. In both instruments, a section of the questions related to 'Information exchange and communication'. The open-ended survey questions were:

- How did you receive bushfire recovery information beyond the 2009 Gippsland bushfires?

- What sources of information did you find to be most reliable and trustworthy?

- With whom did you exchange and share recovery support information?

- How did you stay connected with others beyond the 2009 Gippsland bushfires?

The semi-structured interview questions expanded on the survey questions:

- Thinking about your recovery information sharing beyond the 2009 Gippsland bushfires, what information sources were the most useful and trustworthy?

- How would you liked to have received it after the 2009 Gippsland bushfires?

- What social media did you use beyond the 2009 Gippsland bushfires?

Of the 20 young adults who participated in the research, 17 completed a survey questionnaire with open-ended questions.
Of the 17,10 also participated in the telephone interviews. In addition, 3 participants chose to undertake the interview only. Thus, data was collected from 17 survey completions and 13 telephone interviews. The written survey responses plus and interview audio transcripts were thematically analysed by hand due to the small dataset. The resulting qualitative data informs the findings in this paper.

\section{Findings and discussion}

Relating to 'Information exchange and communication', 3 subthemes emerged. These were:

- $\quad$ supportive disaster communications for young adults

- the strength of social media for communications during and after disasters

- the creation and role of virtual communities.

To emphasise these, some of the responses are provided to highlight various facets. Participants were given pseudonyms for anonymity.

\section{Supportive disaster communications for young adults}

A research question asked the participants how to deliver information to young adults. When Harriet was asked what communication she considered would connect young adults to recovery supports, she asserted that a variety of communication strategies were beneficial:

[P]robably a combination of ways to contact people through social media [such as] Facebook. [And] texting. But ... like I said before... I did not know about the government website. I'm not sure if others knew about the government website or other sources that offer help.

Harriet

Felicity suggested that information delivery needed to be flexible and 'tailored', especially to reach young adults:

I think specifically some people my age needed help finding information - you're expected to find things yourself and you're supposed to have such easy access to digital communications, [people] think you can find it quite easily. But some didn't have access and did not know where to get the information. So I think that, yeah, definitely, digital communications are not only the preferred way to get information. Perhaps information needs to be tailored to [young adults].

Felicity

For Oscar, he reflected that young adults:

... felt like they didn't know where to go to get information and they felt like they didn't have an opportunity to speak on a level platform.

Oscar 
" RESEARCH

Oscar's final point articulates one of the challenges of one-way communication and the lack of agency and voice for young adults in traditional and formal communications.

A noteworthy deficit in youth disaster resilience appears to be poor communication, with perceived inadequacies in the formal information exchange. Many young adults in acute need during the bushfires reported that they did not know of essential recovery supports available to them.

\section{Social media for communications during and after disasters}

The young adults in this study searched for information and support through their personal social media networks. According to Howell and Taylor (2012), social media may be an important factor in the promotion of connectedness and can play a significant role in the promotion of psychological first aid and support.

Beyond general communications, respondents said they turned to social media and its potential to send and receive information. Louise, along with other participants, was unsure about any single method of contact being more helpful than another. However, she thought that social media options such as Facebook were a good starting point:

... people would message you but a lot of people didn't have people's contact details so that's why Facebook was a starting point ... you can message anyone and say ' $h$, how you going, can I get your number, can I get your email address?' It's a starting point; it's a way of connecting with people and then from there you can choose what kind of avenues you want to take, but in terms of people getting information, I know a lot of people weren't aware which websites to go to.

\section{Louise}

Like others in this study who had moved elsewhere after the bushfires, Oscar reported social media as being useful in keeping connected. His comments demonstrate the changing nature of social media platforms:

Even though I didn't have direct access to everyone's numbers, social media was extremely beneficial in keeping in contact with people whether they were still in Victoria or other parts of Australia or even overseas for that matter. Now there's lots of combinations of Facebook, Twitter, we use Instagram for just sending direct photos through, Viber, WhatsApp and a whole lot of applications that people use.

Oscar

While social media platforms have demonstrated potential as a psychosocial recovery tool, their use was hindered by a lack of policies and procedures around the time of the 2009 Gippsland bushfires. Support agencies claimed they were uncertain how to use social media to reach young adults (Australian Red Cross 2012). While many emergency services organisations use social media to transmit information and monitor feedback for situational awareness, governments at the local and national leve could better use social media for efficient information dispersal and ease of communication and build public participation, engagement and empowerment (Lovira \& Valentina 2020).

It is important to note that social media is not a magic solution for the challenges faced by communicators during and after a disaster. Validity of information is a key concern. As Willems and Bateman (2013) note, errors and inaccuracies can be magnified, especially when peers are considered more trustworthy sources of information than information coming through formal communications channels. In a recent United Kingdom poll, fewer than 40 per cent of the 2000 adults surveyed chose an expert as the most trustworthy authority for information and advice, while the majority indicated that anything a friend shared on social media was fact (South West News Service 2019). Willems (2015) outlined additional limitations to relying solely on social media during disasters including Internet overload, service supply and connectivity, power sources and personal safety.

\section{Role of virtual communities}

The strength of social media was discussed by participants in enabling the establishment of, or participation in, virtual communities of support. In particular, Facebook was mentioned as offering a means of keeping people dispersed across wide geographic areas connected, especially through the creation of specific group pages established to provide support for agespecific cohorts. Oscar established one such virtual community when he set up a Facebook group. He said:

The fact was I knew [young] people who were in desperate need of support and they just weren't getting any assistance. They didn't know where to get the information from. They weren't in a mental position to ask for the information nor did they feel that they were entitled to it, even though they definitely were. They felt that other people were more needing of support.

Oscar

While Oscar had moved away after the 2009 Gippsland bushfires, he still connected to his virtual community long after the event.

Aldrich (2012) has written extensively on how 'social networks and connections form the core engine of recovery after even the most devastating of events' (p.viii). Virtual communities grow and thrive in social media (Lovari \& Bowen 2019) to meet the specific needs of those involved, allowing a person's sense of place to go beyond a physical location. Facebook pages offer a means of keeping young adults in wide geographic areas connected because a person's sense of place often goes beyond physical location to the virtual world of social media (Ridings \& Gefen 2004). Aldrich (2012, p.163) indicated that more research needs to be conducted into how effective virtual communities are 'creating and maintaining social ties and disseminating critical facts'. This has been supported in recent reports (We are Social 2020). 


\section{Research limitations}

There are limitations to this research. Small research cohorts are often salient features of qualitative research. Scale is not crucial and there is no need for estimates of statistical significance because a phenomenon may only occur once in order to be significant (Braun \& Clarke 2013). Sample size does affect the generalisation of the findings to other contexts. Due to the small sample size, themes were not analysed for contextual deviations and no comparisons were made between the different fire-affected regions in the 2009 Gippsland bushfires. Had it been done, variations may have occurred. Qualitative research requires researcher reflexivity on 'insider' versus 'outsider' status with the research population. On one hand, a potential bias could have been the 'outsider' demographic of the authors who are not young adults. Participants may not have shared freely. On the other hand, researcher 'insider' status of having experienced Black Saturday and the 2009 Gippsland bushfires may have limited objectivity. In spite of these considerations, the research specifically sought the perspectives through narrative of young adults as a particular demographic in disaster recovery.

\section{Conclusion}

Young adults, as a specific age cohort, are important to consider in research on emergencies and disasters. This article has described the theme of age-specific information and communication that emerged from research conducted on the psychosocial recovery of young adults following the 2009 Gippsland bushfires. Three learnings have emerged. First, there is a need to identify the gaps in information processes and support systems for young adults. Second, young adults are mobile and may miss out on place-based information and support. However, use of virtual communities can provide support that is not location-reliant. Finally, virtual communities are a preferred source of information and support for young adults.

These findings point to the need for continued age-specific research with young adults, especially the role of social media and virtual communities to aid recovery. While researchers and practitioners support the opinion that social media can be a means by which to develop disaster resilience, it is noted that social media is not a panacea. We encourage further research on young adults' use of social media and virtual communities as part of their psychosocial supports.

\section{References}

Aldrich DP 2012, Building resilience: Social capital in post-disaster recovery. Chicago, IL: University of Chicago Press.

Anderson M \& Jiang J 2018, Teens, social media \& technology. Pew Research Center. At: www. pewresearch.org/internet/2018/05/31/ teens-social-media-technology-2018\%.

Au AT 2011, Analysis of command and control networks on Black Saturday, Australian Journal of Emergency Management, vol. 26, no. 3, pp.20-29.
Australian Bureau of Statistics (ABS) 2013, 4102.0 - Australian social trends: Young adults then and now. At: www.abs.gov.au/ AUSSTATS/abs@.nsf/Lookup/4102.0Main+Features40April+2013.

Beetham H, McGill L \& Littlejohn A 2009, Thriving in the 21st Century: Learning Literacies for the Digital Age (LLiDA) Final Project Report. Glasgow: The Caledonian Academy, Glasgow Caledonian University. At: www.webarchive.org.uk/wayback/ archive/20140613220103/http://www.jisc.ac.uk/media/ documents/projects/lidareportjune2009.pdf.

Blanchard H, Carvin A, Whittaker ME, Fitzgerald M, Harman W \& Humphrey B 2010, White paper: the case for integrating crisis response with social media. Washington, DC: American Red Cross. At: www.scribd.com/doc/35737608/White-Paper-The-Case-forIntegrating-Crisis-Response-With-Social-Media.

Braun V \& Clarke V 2013, Successful qualitative research: A practical guide for beginners. London: Sage.

Cox R, Scannell L, Heykoop C, Tobin-Gurley J \& Peek L 2017, Understanding youth disaster recovery: The vital role of people, places, and activities, International Journal of Disaster Risk Reduction, vol. 22, pp.249-256. doi:10.1016/j.ijdrr.2017.03.011

Department of Human Services Emergency Management Branch (DHSEMB) 2013, Emergency management planning for children and young people: Planning guide for local government. Melbourne: Health and Human Services Emergency Management, Victorian Government Department of Human Services. At: https:// earlytraumagrief.anu.edu.au/files/EM-planning-for-children-andyoung-people-web.pdf.

Dufty N 2012, Using social media to build community disaster resilience, The Australian Journal of Emergency Management, vol. 27, no. 1, pp.40-45. At: https://knowledge.aidr.org.au/resources/ajemjan-2012-using-social-media-to-build-community-disaster-resilience

Fergie G, Hunt K \& Hilton S 2016, Social media as a space for support: young adults' perspectives on producing and consuming user-generated content about diabetes and mental health, Social Science \& Medicine, vol. 170, pp.46-54. doi:10.1016/j. socscimed.2016.10.006

Fletcher S, Cox R, Scannell L, Heykoop C, Tobin J \& Peek L 2016, Youth Creating Disaster Recovery and Resilience: A Multi-Site Arts-Based Youth Engagement Research Project, Children, Youth and Environments, vol. 26, no. 1, pp.148-163. doi: 10.7721/ chilyoutenvi.26.1.0148

Forbes R, Jones R \& Reupert A 2012, In the wake of the 2009 Gippsland fires: Young adults' perceptions of post-disaster social supports, Australian Journal of Rural Health, vol. 20, no. 3, pp.119-125. doi: 10.1111/j.1440-1584.2012.01271.x

Forbes RJ, Willems I \& Simmons M 2021, The role of acknowledgment in the psychosocial recovery of young adults in disaster events, Australian Journal of Emergency Management, vol.36, no. 2, pp.42-47.

Fugate C 2011, Understanding the power of social media as a communication tool in the aftermath of disasters. Washington, D.C.: Senate Committee on Homeland Security and Governmental Affairs, Subcommittee on Disaster Recovery and Intergovernmental Affairs. 
Kaplan A \& Haenlein M 2011, Users of the world, unite! The challenges and opportunities of Social Media, Business Horizons, vol. 53, no. 1, pp.59-68.

Keim M, Noji E \& Keim M 2011, Emergent use of social media: A new age of opportunity for disaster resilience, American Journal of Disaster Medicine, vol. 6, no. 1, pp.47-54.

Lovari A \& Bowen SA 2019, Social media in disaster communication: A case study of strategies, barriers, and ethical implications, Journal of Public Affairs, vol. 20, no. 1, e1967. doi:10.1002/pa.1967

Lovari A \& Valentini C 2020, Public Sector Communication and Social Media: Opportunities and Limits of Current Policies, Activities, and Practices, in Vilma Luoma-aho and María-José (Eds.), The Handbook of Public Sector Communication, First Edition, pp.315-328. Hoboken, NJ: John Wiley and Sons.

Organisation for Economic Co-operation and Development (OECD) 2001, The Well-being of Nations: The Role of Human and Social Capital, OECD Publishing, Paris. doi: 10.1787/9789264189515-en

Page-Tan C 2020, Bonding, bridging, and linking social capital and social media use: How hyperlocal social media platforms serve as a conduit to access and activate bridging and linking ties in a time of crisis, Natural Hazards. 1-22. doi: 10.1007/s11069-020-04397-8

Palen L, Vieweg S, Liu S \& Hughes A 2009, Crisis in a networked world: Features of computer-mediated communication', Social Science Computing Review, vol. 27, no. 4, pp.467-480. doi:10.1177/0894439309332302

Pangrazio L \& Selwyn N 2018, 'It's not like it's life or death or whatever': Young people's understandings of social media data, Social Media + Society, vol. 4, no. 3, pp.1-9. doi: 10.1177/2056305118787808

Paton D \& Irons M 2016, Communication, sense of community, and disaster recovery: A Facebook case study, Frontiers in Communication, vol. 1, no. 4, pp.1-12. doi: 10.3389/fcomm.2016.00004

Peek L, Tobin-Gurley J, Cox RS, Scannell L, Fletcher S \& Heykoop C 2016, Engaging youth in post-disaster research: Lessons learned from a creative methods approach, Gateways: International Journal of Community Research and Engagement, vol. 9, no. 1, pp.89-112. doi: 10.5130/ijcre.v9i1.4875

Ridings CM \& Gefen D 2004, Virtual community attraction: Why people hang out online. Journal of Computer-Mediated Communication, vol. 10, no. 1. doi: 10.1111/j.1083-6101.2004. tb00229.x

South West News Service 2019, Many trust what their friends post on social media more than experts, poll claims, The Independent. At: www.independent.co.uk/extras/lifestyle/socialmedia-facebook-friends-trust-experts-a9015636.html.

Smith A \& Anderson M 2018, Social media use in 2018. Pew Research Center. At: www.pewinternet.org/wp-content/uploads/ sites/9/2018/02/PI_2018.03.01_Social-Media_FINAL.pdf.

Teague B, McLeod R \& Pascoe S 2010, 2009 Victorian Bushfires Royal Commission Final Report. Melbourne: Victorian Bushfires
Royal Commission. At: http://royalcommission.vic.gov.au/ finaldocuments/summary/PF/VBRC_Summary_PF.pdf.

Toffler A 1980, The third wave: The classic study of tomorrow. New York: Bantam Books.

Vieweg S, Hughes AL, Starbird K \& Palen L 2010, Microblogging during two natural hazards events: what twitter may contribute to situational awareness, in Proceedings of the SIGCHI Conference on Human Factors in Computing Systems, pp.1079-1088. At: www.pensivepuffin.com/dwmcphd/syllabi/insc547_wi13/papers/ microblog/vieweg.et.al.TwitterAwareness.CHI10.pdf.

We are Social 2020, Digital in 2020. At: https://wearesocial.com/ digital-2020.

White CM, 2012, Social Media, Crisis Communication, and Emergency Management: Leveraging Web2.0 Technology, CRC Press, Boca Raton.

Willems J 2013, M-learning via smartphones and social networks during emergencies and disasters - An Australian story. In Z. Berge and L. Muilenburg (Eds.), Handbook of Mobile Learning, pp.511-523. London: Routledge.

Willems J 2015, There's something not quite right about Not Quite Right: The Role of personal Humour via Social Media in Crises for Individual and Community Resilience', Proceedings of the European Conference of Social Media (ECSM) 2015, pp.454-459.

Willems J \& Bateman D 2013, Facing up to it: The practice of blending formal and informal learning opportunities in higher education contexts. In G. Trentin \& M. Repetto (Eds.), Using network and mobile technology to bridge formal and informal learning, pp.53-79. Oxford, UK: Chandos Publishing.

\section{About the authors}

Dr Julie Willems is a researcher at Monash University and holds qualifications in nursing, education and the humanities. She received an auDA Foundation research grant in 2011 for the i-Survive Project that explored the use of 'back channel' communications via mobile social media during emergencies and disasters.

Dr Rouve Jan Forbes has a background in community health nursing. She received a 'Certificate of Appreciation' from the Australian and Victorian governments for her significant commitment and contribution to the recovery and rebuilding efforts following the 2009 Gippsland bushfires. She completed her PhD at Monash University.

Dr Margaret Simmons is a researcher at Monash University. She teaches a social perspective on health in the graduate medical program and was the recipient of the Vice-Chancellor's Award for Excellence in Inclusion and Diversity in 2020. 